\title{
Silver diamine fluoride: An operative dentistry perspective
}

\author{
Quock RL ${ }^{1, *}$ \\ Department of Restorative Dentistry \& Prosthodontics, University of Texas School of Dentistry, 7500 Cambridge, Houston, TX 77054, USA
}

\begin{abstract}
The rationale for much of operative dental therapy is to address local tooth destruction due to the dental caries process. While mechanical tooth preparation and restorative biomaterial concepts continue to evolve, attention should also be paid to the biological challenges of the caries disease. Silver diamine fluoride is a therapeutic agent that shows great promise for the operative dentist due to its ability to stimulate arrest of active caries and prevent new lesions. Clinical and laboratory studies continue to demonstrate silver diamine fluoride's efficacy in treating dental caries. This practical review summarizes the current evidence for its use in operative dentistry.
\end{abstract}

Keywords: caries; caries arrest; fluoride; silver; silver diamine fluoride

\section{Introduction}

The operative preparation and restoration of teeth has long been an integral part of acute dental caries treatment. Cavitated lesions are traditionally targeted for operative treatment because vital enamel substructure has been lost, rendering complete remineralization impossible. Indeed, a well-sealed restoration can be a strong contributor to the arrest of the caries lesion, seemingly regardless of the level of excavation [1, 2].

Although the science seems to suggest that not all caries affected dentin needs to be removed prior to restoration [3], there is hesitation in the practicing community to adopt this perspective $[4,5]$. The reluctance to "leave caries" before restoration relates to skepticism of caries arrest under the restoration. Not being able to clinically observe dentin hardness may be uncomfortable for clinicians [4, 5].

If the growing scientific evidence supporting minimal tooth preparation has not been enough to convince clinicians to be less invasive, perhaps an emerging therapy will help to bridge the gap. Silver diamine fluoride (SDF) is a solution that has demonstrated through clinical research the ability to arrest active caries lesions, and also prevent the occurrence of new ones. Clinical manifestation of arrest is typically hardening of the dentin surface to the point of resistance to penetration with a sharp probe, usually accompanied by color change. This practical review aims to summarize the current understanding of silver diamine fluoride and direct the reader toward applications in daily operative dental practice.

\section{Composition and action}

Silver diamine fluoride $\left[\mathrm{Ag}\left(\mathrm{NH}_{3}\right)_{2} \mathrm{~F}\right]$ is a clear, ammonia solution with two active ingredients - silver and fluoride $[7,8]$. It has been commercially available in Asia and South America for at least three decades, but only recently was introduced to the USA market. In 2014, the United States Food and Drug Administration approved SDF as a dentin sensitivity agent, similarly to fluoride varnishes. The use for anticaries purposes will be off-label.

Although variances exist in application protocols, simply scrubbing SDF onto the surface of a cavitated lesion with a brush or small cotton pellet appears to be an acceptable approach. A three-part mechanism of action has been proposed for SDF. First, silver salts formed on the dentin surface stimulate sclerosis/calcification [8]. Laboratory studies indicate some penetration of silver ions into dentin [9] as well as detectable increase in hardness of arrested lesions [10]. Also, the intermediate product silver nitrate has an antibacterial effect [8]. A number of in vitro studies have demonstrated an antimicrobial action of SDF [11-14]. And not surprisingly, fluoride is active in remineralization and prevention [8]. The most commonly studied and marketed form of this product, 38\% SDF, presents approximately

*Corresponding author: Dr. Ryan Quock, Department of Restorative Dentistry \& Prosthodontics, University of Texas School of Dentistry, 7500 Cambridge, Houston, TX 77054, USA. Tel.: (713) 486-4276; Fax: (713) 4864353; Email: Ryan.Quock@uth.tmc.edu

Received 3 March 2016 Revised 25 May 2016 Accepted 7 June 2016 Published 14 June 2016

Citation: Quock RL, Silver diamine fluoride: An operative dentistry perspective. J Oper Esthet Dent. 2016; 1(2):6-9. DOI: 10.14312/2398029X.2016-2

Copyright: () 2016 Quock RL. Published by NobleResearch Publishers. This is an open-access article distributed under the terms of the Creative Commons Attribution License, which permits unrestricted use, distribution and reproduction in any medium, provided the original author and source are credited. 
44,800 ppm of fluoride. As a comparison, five percent sodium fluoride varnish presents 22,600 ppm of fluoride. Arrested lesions treated with SDF show superficial bands of increased calcium and phosphate [15]. It appears that SDF slows down the progression of lesions [16].

Silver diamine fluoride is not known to elicit any consistent adverse pulpal effects [17]. It may actually contribute to tertiary dentin deposition when incorporated into indirect pulp treatment [18]. Systemic concerns secondary to ingestion after SDF application are also minimal, with regard to both fluoride and silver levels in the blood [19]. The primary adverse effect resulting from caries management with SDF is esthetic in nature. Lesions arrested by SDF tend to exhibit darkened color. Restorative management of this possible inconvenience will be addressed later in this review.

\section{Clinical efficacy}

Concomitant to the FDA approval, it appears that the application of SDF in caries management is gaining momentum. Dental schools are incorporating SDF into theoretical and practical curriculum [20]. Much of the rationale for SDF use is based upon its effectiveness in arresting caries, especially in dentin (65.9\%) [21]. For the purpose of this review, and based on available clinical studies of SDF [22-26], arrest will be described as hardening or resistance of previously carious dentin to penetration with a sharp probe - this is often accompanied by darkening in color and, in theory, lack of progression of the lesion. Since 38\% SDF is the most studied formulation, and widely available commercially, summaries of clinical studies that tested this product are presented below (Table 1).

Table 1 Summary of clinical studies in caries arrest efficacy of silver diamine fluoride.

\begin{tabular}{|c|c|c|}
\hline $\begin{array}{l}\text { Author, Year } \\
\text { [Reference] }\end{array}$ & Method (Sample size) & $\begin{array}{l}\text { Comparative } \\
\text { percentage arrest of } \\
\text { caries }\end{array}$ \\
\hline $\begin{array}{l}\text { Chu et al, } 2002 \\
{[22]}\end{array}$ & $\begin{array}{l}\text { Primary teeth, } 30 \text { months } \\
(n=375) \\
\text { Exp1 }=38 \% \text { SDF annually } \\
\text { Exp2 }=5 \% \text { NaF } 4 \times / \text { year } \\
\text { Control = no treatment }\end{array}$ & $\begin{array}{l}\text { Exp1>Exp2, Control } \\
(p<0.001)\end{array}$ \\
\hline $\begin{array}{l}\text { Llodra et al, } \\
2005 \text { [23] }\end{array}$ & $\begin{array}{l}\text { Primary and permanent teeth, } \\
36 \text { months }(n=373) \\
\text { Exp }=38 \% \text { SDF } 2 x / \text { year } \\
\text { Control = no treatment }\end{array}$ & $\begin{array}{l}\text { Exp }>\text { Control } \\
(p<0.001)\end{array}$ \\
\hline $\begin{array}{l}\text { Yee et al, } 2009 \\
{[24]}\end{array}$ & $\begin{array}{l}\text { Primary and permanent teeth, } \\
24 \text { months ( } n=976) \\
\text { Exp1 }=38 \% \text { SDF at baseline } \\
\text { Exp2 }=12 \% \text { SDF at baseline } \\
\text { Control = no treatment }\end{array}$ & $\begin{array}{l}\text { Exp1>Exp2, Control } \\
(p<0.001)\end{array}$ \\
\hline $\begin{array}{l}\text { Zhi et al, } 2012 \\
\text { [25] }\end{array}$ & $\begin{array}{l}\text { Primary teeth, } 24 \text { months } \\
(n=181) \\
\text { Exp1 }=38 \% \text { SDF annually } \\
\text { Exp2 }=38 \% \text { SDF } 2 \text { x/year } \\
\text { Exp3 }=\text { Glass ionomer annually }\end{array}$ & $\begin{array}{l}\text { Exp2>Exp1, Exp3 } \\
(p=0.007)\end{array}$ \\
\hline
\end{tabular}

In 2002, Chu and colleagues published results of a 30 months study of cavitated anterior primary tooth caries in Chinese pre-school children [22]. Three hundred seventy five participants (aged 3-5) were divided into a control group and four experimental groups as follows: yearly applications of 38\% SDF or quarterly applications of $5 \% \mathrm{NaF}$ varnish (half of each modality experienced excavation of soft dentin prior to fluoride treatment, while half received no mechanical preparation). Cavities were not restored. Silver diamine fluoride groups, regardless of whether caries excavation took place or not, presented with nearly twice as many arrested lesions as varnish and control groups [22].

Llodra et al., published the results of their 36 months study of cavitated primary teeth and permanent molars in 2005 [23]. Three hundred seventy three schoolchildren (average age 6) participated, with experimental groups receiving 38\% SDF every six months for the duration of the study. Soft carious dentin was removed from permanent molars, while no excavation was performed on primary teeth. A significantly greater percentage of SDF treated lesions experienced arrest compared to the control group [23]. SDF treated teeth also experienced less than half the number of new decayed surfaces, demonstrating its preventive potential [23].

A study of 976 Nepalese children (aged 3-9) published in 2009 involved cavitated primary teeth [24]. The teeth were not excavated prior to application of either $12 \%$ or $38 \%$ SDF, which were applied only once at baseline. Follow up occurred every six months for two years, with no restorations placed. 38\% SDF groups experience significantly more caries lesion arrest (more than two surfaces on average at the two year mark) than $12 \%$ SDF or control groups [24].

Zhi and colleagues studied one hundred eight one Chinese schoolchildren with cavitated caries lesions [25]. Superficial soft dentin was removed with prior to one of the following three treatments: annual application of 38\% SDF, biannual application of $38 \%$ SDF, and annual application of lowviscosity glass ionomer. The caries arrest rate at 24 months was significantly better for the biannual applications of SDF (91\% arrest rate) [25].

Pediatric populations have drawn the most attention for clinical studies regarding SDF, but adult populations are being targeted as well. A 2013 study of root surfaces in an elderly Chinese population showed significantly better arrest and prevention of root lesions when treated with SDF [26]. Prevention of caries in pits-and-fissures has also been explored, although one study reported that SDF lacked the ability to prevent pit-and-fissure caries [27], another study suggests that annual applications of SDF to occlusal surfaces does prevent caries [28]. Overall, the reported data is favorable: the most recent systematic review, with meta-analysis, of SDF reports an overall dentin caries arrest rate of $65.9 \%$ [21], slightly tempering results from an earlier review [8].

\section{Considerations for use in operative dentistry}

The general procedure for application of SDF to caries lesions is fairly simple. Contraindications include patients with silver allergy and/or ulcerative gingivitis or stomatitis. Following standard infection control protocols, one drop of SDF is placed into a dappen dish (enough for approximately five teeth). Excess bulk saliva is removed, preferably with a saliva ejector, and soft tissue isolation is achieved with a dental dam or cotton rolls/gauze. If a dental dam cannot be 
placed, gingiva in the application area can be coated with a thin layer of petroleum jelly. Tooth surfaces are then gently air dried, and a small brush is used to scrub the SDF onto the target lesion surface for approximately one minute. Rinsing with water is not mandatory, but if desired, should be done so in the presence of a high volume evacuator.

If part of the goal in restoring a cavitated lesion is caries control, then SDF clearly presents an opportunity to ensure arrest of the lesion. Following this rationale, the arrest and hardening of existing dentinal caries by SDF dovetails with the concept of minimally invasive preparation and tooth conservation [29]. It has been demonstrated that SDF does not adversely affect the bond strength of resin composite to dentin, regardless of whether an etch-and-rinse or selfetch adhesive is used [30]. In bovine dentin, SDF seems to enhance the bond strength of glass ionomer cement [31]. These factors appear to justify the addition of SDF to the clinician's armamentarium.

As mentioned earlier, the primary adverse effect of SDF on dentin is the staining of the arrested lesion. There are at least two options to address this possible esthetic challenge. Potassium iodide applied to the SDF treated surface in a two-step process has been investigated previously. The result is a white precipitate, which may be more esthetically pleasing for some patients [32]. Additionally, a glass ionomer or resin-modified glass ionomer liner can be placed over stained axial or pulpal walls to cover over stained areas. This is an interesting option due to the glass ionomer's possible affinity for SDF treated dentin [31].

Once esthetic concerns are addressed by either of the above options, the clinician needs to decide when to restore the cavity. One line of thought is that the longer the SDF treated cavity is able to be exposed to the oral environment, the greater the arrest [7], this may be due to the available minerals in the saliva. If patient and practitioner are willing to delay restoration until clinically detectible arrest is achieved, then the operative dentist may elect to reapply SDF at determined intervals until acceptable arrest occurs. Recent investigation suggests that accelerated arrest can be achieved with three early applications of SDF, each one week apart [33].

Once dentin arrest is observed, the clinician can proceed with typical conservative operative dentistry, removing unsupported enamel and caries at the DEJ with retention of arrested axial or pulpal walls. Full-mouth rehabilitation of teeth subjected to extreme caries insult has been reported, with SDF providing the opportunity to save many otherwise hopeless teeth [34]. Follow up on SDF treated lesions that have been restored should be approached in the same way as any restoration is monitored; the absence of clinical and radiographic evidence of caries activity or progression will relate to success. If recurrent caries or progression is determined, the operator may decide to commence with repair or replacement of the restoration.

\section{Conclusion}

Silver diamine fluoride appears to be effective in arresting active caries lesions, and preventing new ones from occurring. These advantages should be of interest to dental professionals. The use of silver diamine fluoride in dentistry is further supported by its apparent compatibility with existing restorative materials.

\section{Conflicts of interest}

Author declares no conflicts of interest.

\section{References}

[1] Ricketts D, Lamont T, Innes NPT, Kidd E, Clarkson JE. Operative caries management in adults and children. Cochrane Database of Systematic Rev 2013; 28(3):CD003808.

[2] Mertz-Fairhurst EJ, Curtis JW, Ergle JW, Rueggeberg FA, Adair SM. Ultraconservative and cariostatic sealed restorations: Results at year 10. J Am Dent Assoc. 1998; 129(1):55-66.

[3] Kidd E, Fejerskov O, Nyvad B. Infected dentine revisited. Dent Update. 2015; 42(9):808-809.

[4] Schwendicke F, Meyer-Lueckel H, Dorfer C, Paris S. Attitudes and behavior regarding deep dentin caries removal: A survey among German dentists. Caries Res. 2013; 47(6):566-573.

[5] Schwendicke F, Mostajaboldave R, Otto I, Dorfer CE, Burkert S. Patients' preferences for selective versus complete excavation: A mixedmethods study. J Dent. 2016; 46:47-53.

[6] Schwendicke F, Domejean S, Ricketts D, Peters M. Managing caries: The need to close the gap between evidence base and current practice. $\mathrm{Br}$ Dent J 2015; 219(9):433-438.

[7] Walker D, Yee R. Arrest of caries technique (ACT): appropriate technology for the clinician and for disadvantaged communities in Nepal. Accessed on March 2, 2016 at http://www.scribd.com/ doc/32660152/Arrest-of-Caries-Technique\#scribd

[8] Rosenblatt A, Stamford TCM, Niederman R. Silver diamine fluoride: a caries "silver-fluoride bullet." Journal of Dental Research. 2009; 88(2):116-125.

[9] Willershausen I, Schulte D, Azaripour A, Weyer V, Briseno B. Penetration potential of a silver diamine fluoride solution on dentin surfaces. An ex vivo study. Clin Lab. 2015; 61(11):1695-1701.

[10] Chu CH, Lo EC. Microhardness of dentine in primary teeth after topical fluoride applications. J Dent. 2008; 36(6):387-391.

[11] Savas S, Kucukyilmaz E, Celik EU, Ates M. Effects of different antibacterial agents on enamel in a biofilm caries model. J Oral Sci. 2015; 57(4):367-372.

[12] Hamama HH, Yiu CK, Burrow MF. Effect of silver diamine fluoride and potassium iodide on residual bacteria in dentinal tubules. Aust Dent J. 2015; 60(1):80-87.

[13] Mei ML, Chu CH, Low KH, Che CM, Lo EC. Caries arresting effect of silver diamine fluoride on dentine carious lesion with $\mathrm{S}$. mutans and L. acidophilus dual-species cariogenic biofilm. Med Oral Patol Oral Cir Bucal. 2013; 18(6):e824-831.

[14] Mei ML, Li QL, Chu CH, Lo EC, Samaranayake LP. Antibacterial effects of silver diamine fluoride on multi-species cariogenic biofilm on caries. Ann Clin Microbiol Antimicrob. 2013; 12:4.

[15] Mei ML, Ito L, Cao Y, LO EC, Li QL. An ex vivo study of arrested primary teeth caries with silver diamine fluoride therapy. J Dent. 2014; 42(4):395-402.

[16] Chu CH, Mei L, Seneviratne CJ, Lo EC. Effects of silver diamine fluorie on dentine carious lesions induced by Streptococcus mutans and Actinomyces naeslundii biofilms. Int J Paediatr Dent. 2012; 22(1):2-10.

[17] Gotjamanos T. Pulp response in primary teeth with deep residual caries treated with silver fluoride and glass ionomer cement ('atraumatic' technique). Aust Dent J. 1996; 41(5):328-334.

[18] Korwar A, Sharma S, Logani A, Shah N. Pulp response to high fluoride releasing glass ionomer, silver diamine fluoride, and calcium hydroxide used for indirect pulp treatment: An in-vivo comparative study. Contemp Clin Dent. 2015; 6(3):288-292.

[19] Vasquez E, Zegarra G, Chirinos E, Castillo JL, Taves DR, et al. Short term serum pharmacokinetics of diammine silver fluoride after oral application. BMC Oral Health. 2012; 12:60.

[20] Horst JA, Ellenikiotis H, Milgrom PL.UCSF protocol for caries arrest using silver diamine fluoride: Rationale, indications and consent. J Calif Dent Assoc. 2016; 44(1):16-28.

[21] Gao SS, Zhang S, Mei ML, Lo EC, Chu CH. Caries remineralization and arresting effect in children by professionally applied fluoride treatment - a systematic review. BMC Oral Health. 2016; 16(1):12.

[22] Chu CH, Lo EC, Lin HC. Effectiveness of silver diamine fluoride and sodium fluoride varnish in arresting dentin caries in Chinese preschool children. J Dent Res. 2002; 81(11):767-770. 
[23] Llodra JC, Rodriguez A, Ferrer B, Menardia V, Ramos T, et al. Efficacy of silver diamine fluoride for caries reduction in primary teeth and first permanent molars of schoolchildren: 36-month clinical trial. J Dent Res. 2005; 84(8):721-724.

[24] Yee R, Holmgren C, Mulder J, Lama D, Walker D, et al. Efficacy of silver diamine fluoride for arresting caries treatment. J Dent Res. 2009; 88(7):644-647.

[25] Zhi QH, Lo EC, Lin HC. Randomized clinical trial on effectiveness of silver diamine fluoride and glass ionomer in arresting dentine caries in preschool children. J Dent. 2012; 40(11):962-967.

[26] Zhang W, McGrath C, Lo ECM, Li JY. Silver diamine fluoride and education to prevent and arrest root caries among communitydwelling elders. Caries Res. 2013; 47:284-290.

[27] Monse B, Heinrich-Weltzien R, Mulder J, Holmgren C, van Palenstein Helderman WH. Caries preventive efficacy of silver diamine fluoride (SDF) and ART sealants in a school-based daily fluoride brushing program in the Philippines. BMC Oral Health. 2012; 12:52.

[28] Liu BY, Lo EC, Chu CH, Lin HC. Randomized trial on fluorides and sealants for fissure caries prevention. J Dent Res. 2012; 91(8):753758.

[29] Quock RL, Patel SA, Falcao FA, Barros J. Is a drill-less dental filling possible? Med Hypotheses. 2011; 77(3):315-317.

[30] Quock RL, Barros JA, Yang SW, Patel SA. Effect of silver diamine fluoride on microtensile bond strength to dentin. Oper Dent. 2012; 37(6):610616.

[31] Yamaga M, Koide $Y$, Hieda T. Adhesiveness of glass ionomer cement containing tannin-fluoride preparation (HY agent) to dentin-an evaluation of adding various ratios of $\mathrm{HY}$ agent and combination with application diammine silver fluoride. Dent Mater J. 1993; 12(1):36-44.

[32] Craig GG, Knight GM, McIntyre JM. Clinical evaluation of diamine silver fluoride/potassium iodide as a dentine desensitizing agent. A pilot study. Aust Dent J. 2012; 57(3):308-311.

[33] Duangthip D, Chu CH, Lo CM. A randomized clinical trial on arresting dentine caries in preschool children by topical fluorides -18 month results. J Dent. 2016; 44:57-63.

[34] Chu CH, Lee AH, Zheng L, Mei ML, Chan GC. Arresting rampant dental caries with silver diamine fluoride in a young teenager suffering from chronic oral graft versus host disease post-bone marrow transplantation: a case report. BMC Res Notes. 2014; 7:3. 